\title{
Cerebral Palsy-An Update
}

\author{
R Pervin ${ }^{1}$, S Ahmed ${ }^{2}$, R T Hyder ${ }^{3}$, B H N Yasmeen ${ }^{4}$, M Rahman ${ }^{5}$, F Islam ${ }^{6}$
}

1 Dr. Rabeya Pervin Ex-Medical Officer Dept. of Paediatrics Northern International Medical College (NIMC)

2 Dr. Shafi Ahmed

Assistant Professor

Dept. of Paediatrics, NIMC

3

3 Dr. Rumy Tabrez Hyder

Assistant Professor of

Paediatrics, MH Samorita

Medical College and Hospital

${ }^{4}$ Dr. B H Nazma Yasmeen Associate Professor Dept. of Paediatrics, NIMC

${ }^{5}$ Professor Dr. Mizanur Rahman Dept. of Paediatric Neurology BSMMU

${ }^{6}$ Dr. Farooqul Islam Assistant Professor Dr. Sirajul Islam Medical College

Correspondence

Dr. Rumy Tabrez Hyder MBBS, FCPS

Assistant Professor of Paediatrics, MH Samorita Medical College and Hospital e-mail: rumytabrez@yahoo.com

\section{Introduction}

Cerebral palsy is the leading cause of childhood disability affecting function and development and was first described in 1862 by an orthopedic surgeon named William James Little.

Cerebral palsy (CP) describes a group of permanent disorders of the development of movement and posture, causing activity limitation, that are attributed to non- progressive disturbances that occurred in the developing fetal or infant brain.

The motor disorders of cerebral palsy are often accompanied by disturbances of sensation, perception, cognition, communication, and behavior, by epilepsy, and by secondary musculoskeletal problem. So, screening for these conditions should be part of the initial assessment ${ }^{1}$.

Modern brain imaging techniques have shed new light on the nature of the underlying brain injury and studies on the neurobiology of and pathology associated with brain development have further explored etiologic mechanisms.

For classification of $\mathrm{CP}$, use of the four major dimensions of classification listed in table I is recommended.

Table: I. Components of CP classification ${ }^{2}$

\section{MOTOR ABNORMALITIES}

\section{A. Nature and typology of the motor disorder :}

The observed tonal abnormalities assessed on examination (e.g. hypertonia, hypotonia) as well as the diagnosed movement disorders present, such as spasticity, ataxia, dystonia, athetosis.

\section{B. Functional motor abilities :}

The extent to which the individual is limited in his or her motor function, including oromotor and speech function.

\section{ACCOMPANYING IMPAIRMENTS}

The presence or absence of later-developing musculoskeletal problems and/or accompanying nonmotor neurodevelopmental or sensory problems, such as seizures, hearing or vision impairments, or attentional, behavioral, communicative and/or cognitive deficits, and the extent to which impairments interact in individuals with cerebral palsy.

\section{ANATOMICAL AND NEURO-IMAGING FINDINGS}

\section{A. Anatomic distribution:}

The parts of the body (limbs, trunk, bulbar region, etc.) affected by motor impairments or limitations.

\section{B. Neuro-imaging findings:}

The neuroanatomic findings on CT or MRI imaging, such as ventricular enlargement, white matter loss or brain anomaly.

\section{CAUSATION AND TIMING}

Whether there is a clearly identified cause, as is usually the case with post-natal CP (e.g. meningitis, head injury) or when brain malformations are present, and the presumed time frame during which the injury occurred, if known.

\section{Prevalence and incidence}

The overall prevalence of $\mathrm{CP}$ has remained constant in recent years despite increased survival of at-risk preterm infants ${ }^{3}$. In developed countries, the overall estimated prevalence of CP is 2-2.5 cases per 1000 live births. The prevalence of $\mathrm{CP}$ among preterm and very preterm infants is substantially higher ${ }^{4}$. In the developing world, the prevalence of CP is not well established but estimates are 1.5-5.6 cases per 1000 live births ${ }^{5}$.

\section{Etiology and risk factors}

Upto $50 \%$ of CP cases have no identifiable underlying etiology ${ }^{6}$. The etiologies can be classified according to the timing of the insult as prenatal (commonest), natal, or postnatal ${ }^{7}$. Risk factors for CP are multifactorial and can include preterm birth, multiple gestation, intrauterine growth restriction, male sex low Apgar scores, intrauterine infections, maternal thyroid abnormalities, prenatal strokes, birth asphyxia, maternal methyl mercury exposure, and maternal iodine deficiency ${ }^{8}$. There also seems to be an association between autoimmune and coagulation disorders and CP. Preterm infants are at the highest risk for developing CP. The vulnerable brain is harmed during a critical period of development primarily by known CNS complications of prematurity such as intraventricular hemorrhage (IVH) and periventricular leukomalacia $(\mathrm{PVL})^{1}$. PVL is the strongest and most independent risk factor for the development of $\mathrm{CP}^{9}$. A recent study found that cerebral malformations were much more frequent among children with $\mathrm{CP}$ than among all live births in the population ${ }^{10}$. Children with cerebral malformations tends to be of greater gestational age and birth weight, or the product of a twin gestation ${ }^{11}$. Study suggests that genetic abnormalities may cause cerebral palsy. For years it was thought that a difficult birth and other perinatal factors were the leading causes of CP. Now, researchers find that the majority of $\mathrm{CP}$ cases may in fact be caused by genetic abnormalities. There is a growing body of evidence that suggests mutations in multiple genes are responsible for $\mathrm{CP}^{12}$. In about 10 $20 \%$ of patients CP is acquired postnatally mainly because of brain damage from bacterial meningitis, viral encephalitis, hyperbilirubinemia, motor vehicle collisions, falls or child abuse ${ }^{13}$.

Pathogenesis

Cerebral palsy is restricted to lesions of the brain only. The brain lesions of CP occur from the fetal or neonatal period up to early childhood ${ }^{14}$. Insults resulting in neuronal loss can be 1) cortical 
(pyramidal), resulting in spasticity, 2) basal ganglion (extrapyramidal), resulting in abnormal movements such as choreoathetosis, 3) cerebellar, resulting in hypotonia, or 4) mixed. Spastic CP is the most common type, accounting for up to $75 \%$ of cases ${ }^{15}$; and except in mild cases spastic CP can be readily diagnosed in the first few days of life. A smaller percentage of children with $\mathrm{CP}$ demonstrate extrapyramidal (dyskinetic) features, and kernicterus (bilirubin encephalopathy) is the leading cause of extrapyramidal $\mathrm{CP}^{1}$. The athetoid form cannot usually be diagnosed early, because one cannot be sure until athetoid movement develops which may not be one or two years after birth. Congenital ataxia cannot be diagnosed until about six months, because it is dependent on certain purposive movement not found before then, but tremor can be diagnosed early certainly by the time the baby is able to sit ${ }^{8}$. Hypotonic cerebral palsy occurs rarely; however, most children progress to other $\mathrm{CP}$ subtypes. Mixed $\mathrm{CP}$ occurs when the child displays a combination of features, such as spasticity and choreoatheosis ${ }^{1}$.

Cerebral injury before the 20th week of gestation can result in a neuronal migration deficit; injury between the 26th and 34th weeks can result in periventricular leukomalacia; injury between the 34th and 40th weeks can result in focal or multifocal cerebral injury ${ }^{16}$. The brain lesions seen in preterm infants include germinal matrix/ intraventricular hemorrhage and white matter damage.

An algorithm for the evaluation of the child with $\mathrm{CP}$ according to American Academy of Neurology ( AAN) practice parameter on CP (2004)

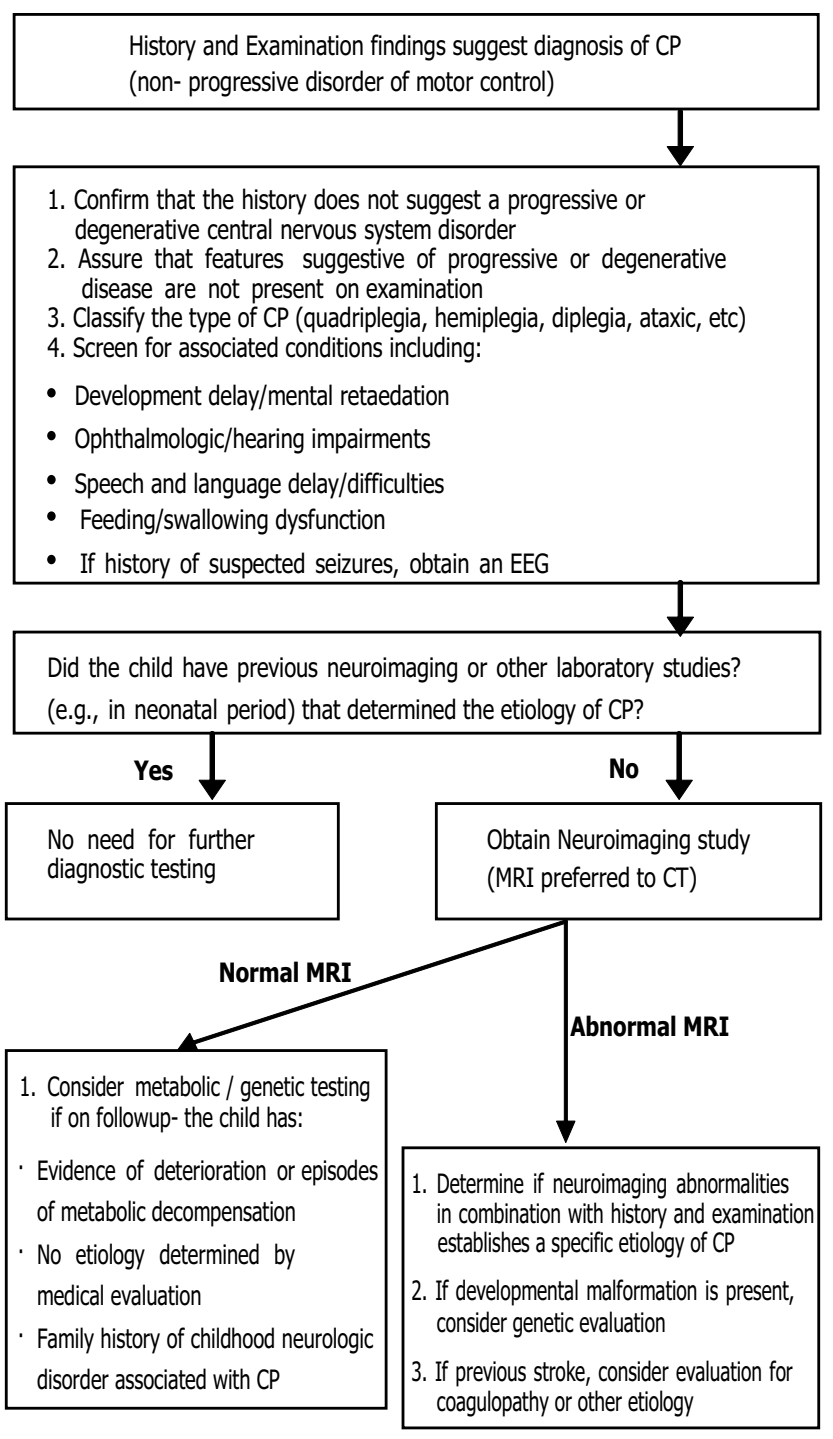

hypoxic ischemic encephalopathy (HIE) occurs in 3-5/1000 live births. Although not responsible for the majority of $\mathrm{CP}$ in term infants, HIE still forms the largest single subgroup of neonatal encephalopathy (NE) accounting for around $20 \%$ of all cases of cerebral palsy in term infants ${ }^{17}$.

\section{Diagnosis}

The diagnosis of cerebral palsy is generally made based on the clinical picture. A comprehensive history for risk factors and genetic background, complete physical and neurological examinations are mandatory for accurate diagnosis. Serial developmental evaluations may be necessary in the young child for proper diagnosis and follow up. The differential diagnosis of cerebral palsy includes metabolic and genetic disorders. Genetic evaluation should be considered in patients with congenital malformations (chromosomes) or evidence of metabolic disorders. The Gross Motor Function Measure (GMFM) is standardized observational instrument designed and validated to measure Gross Motor Function Measure over time in children with cerebral palsy. The 2004 American Academy of Neurology (AAN) practice parameter on $\mathrm{CP}$ developed an algorithm for the evaluation of the child with cerebral palsy ${ }^{18}$.

\section{Imaging Studies}

Most (83\%) children with CP have abnormal neuroradiological findings, with white matter damage the most common abnormality.

a. Cranial ultrasonography performed in the early neonatal period can delineate clear-cut structural abnormalities and show evidence of hemorrhage or hypoxic-ischemic injury.

b. CT scanning of the brain helps identify congenital malformations, intracranial hemorrhage, and periventricular leukomalacia in infants more clearly than ultrasonography.

c. MRI is preferred over CT scanning because it defines cortical and white matter structures and abnormalities more clearly than any other method. It also allows for the determination of appropriate myelination for a given age ${ }^{19}$. Infants and children can be studied with MRI, and ultrafast MRI permits evaluation of the fetal CNS. Results from fetal MRI have led to better understanding of many brain abnormalities. All children with $\mathrm{CP}$ should have an MRI scan to provide information on the timing and extent of the lesion ${ }^{20}$. So, neuroimaging is currently recommended as a standard evaluation in children with $\mathrm{CP}$ and MRI is the diagnostic neuroimaging study of choice ${ }^{21}$.
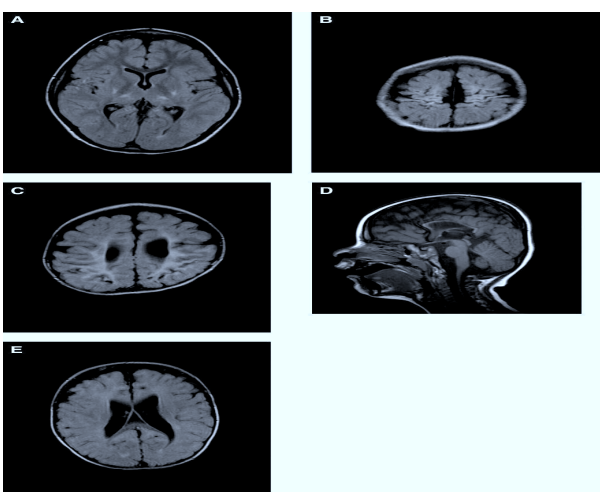

Figure 1 : (A) Eight-year-old girl with cerebral palsy: spastic diplegia grade III, right >left. Focal epilepsy. An axial-plane, fluid-attenuated inversion recovery sequence revealed bilateral hyperintensive lesions of the basal ganglia and thalamus. (B) Two-year-old boy with cerebra palsy: tetraplegia grade IV, right > left. Intractable epilepsy. An axial-plane, fluid-attenuated inversion recovery sequence revealed bilateral lesion of the central cortex, atrophy, and increased signal intensity of the central gyri. (C) Two-year-old boy with cerebral palsy: spastic diplegia grade III, left > right. Focal epilepsy. An axial-plane, fluid-attenuated inversion recovery sequence revealed bilateral hyperintensity of periventricular white matter, and enlargement of the cerebrospinal fluid spaces (leukomalacia and brain atrophy). (D) Same patient as in C. Magnetic resonance imaging, sagittal plane, T1-weighted image: thinning of the corpus callosum. (E) One-year-old boy with cerebral palsy: spastic diplegia grade II, left > right. An axial-plane, fluid-attenuated inversion recovery sequence revealed symmetrical enlargement of the lateral ventricles. 


\section{Complications}

Complications of CP include spasticity and contractures; feeding difficulties, choking, gagging, drooling, aspiration pneumonia, GERD, communication difficulties; osteopenia, osteoporosis, fractures, pain, bladder dysfunction, sleep disturbances and functional GI abnormalities contributing to bowel obstruction, vomiting, and constipation ${ }^{13}$.

\section{Management}

The management of patients with cerebral palsy must be individualized based on the childs clinical presentation and requires a multidisciplinary approach that provides a combination of interventions ${ }^{22}$. Specific treatment options include physical, occupational and speech therapy, drug treatment for spasticity (local, intrathecal, systemic) and orthopedic and neurosurgical interventions. The primary care physician should provide anticipatory guidance, immunizations, and developmental surveillance ${ }^{1}$.

Children with CP are at high risk of incomplete and delayed immunization and their increased vulnerability to the complications of vaccine-preventable diseases ${ }^{23}$. All routine immunization should be provided, including pertussis vaccine, even if the child has epilepsy. Progressive uncontrolled epilepsy indicates DT rather than DPT vaccine. Annual influenza vaccine and pneumococcal immunization is recommended for those with recurrent or chronic respiratory illnesses ${ }^{1}$. Spasticity and other forms of muscle over activity caused by cerebral palsy may impair function or ease of care or may cause discomfort or poor body image. The treatment program for a child with spasticity may include allied health therapy, exercise, casting, constraint-induced therapy, oral medications, chemodenervation, intrathecal baclofen, selective dorsal rhizotomy, and orthopedic surgery. Techniques may be combined for greater efficacy and better tailoring to the needs of the child $^{19}$. Systemic treatments for spasticity include Baclofen, Diazepam, Dantrolene and Tizanidine alone or in combination. Baclofen is the most commonly used oral medication in children with generalized spasticity.

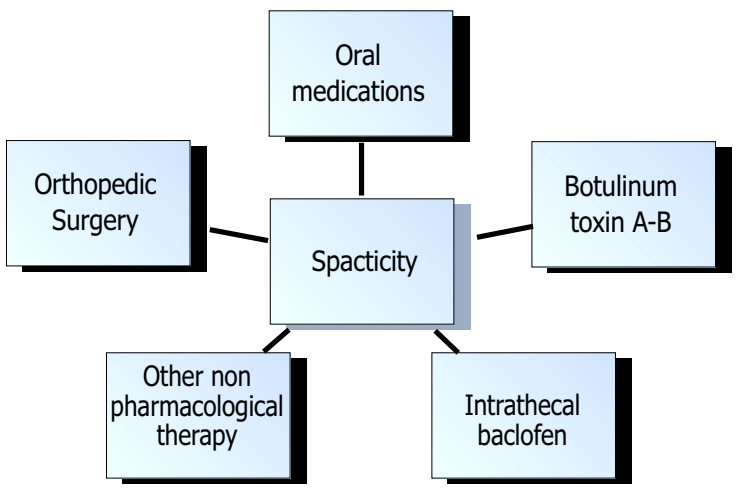

Figure 2 : Global therapeutic approach to the child with spasticity

\begin{tabular}{|c|c|}
\hline Drug & Dosage \\
\hline Baclofen & $\begin{array}{l}2-7 \text { years: } 10-15 \mathrm{mg} / \text { day divided every } 8 \mathrm{~h} \text {; titrate dose every } \\
3 \text { days in increments of } 5-15 \mathrm{mg} / \text { day to a max of } 40 \mathrm{mg} / \text { day } \\
\geq 8 \text { years: Titrate dosage as above to a max of } 60 \mathrm{mg} / \text { day }\end{array}$ \\
\hline Diazepam & $0.12-0.8 \mathrm{mg} / \mathrm{kg} /$ day divided every $6-8 \mathrm{~h}$ \\
\hline $\begin{array}{l}\text { Dantrolene } \\
\text { sodium }\end{array}$ & $\begin{array}{l}0.5 \mathrm{mg} / \mathrm{kg} / \mathrm{dose} \text { twice daily; increase frequency to } 3-4 \text { times } \\
\text { a day at 4- to } 7 \text { - day intervals }\end{array}$ \\
\hline Clonidine & $5-10 \mathrm{mcg} / \mathrm{kg} / \mathrm{day}$, in 2-3 divided doses \\
\hline Tizanidine & pediatric dosing is unavailable \\
\hline
\end{tabular}

* Oral baclofen is FDA approved for use in children 12 years of age and older.
Children with spasticity that are refractory or intolerant to oral medications may be candidates for intrathecal baclofen therapy. In general, oral medications and intrathecal baclofen are used for treating generalized spasticity, while chemodenervation agents (botulinum toxin, phenol or alcohol) are used to treat localized spasticity ${ }^{24}$.

\section{Chemical denervation}

Injection Botulinum toxin type A can be an effective treatment for pain in children with hip spasms and cerebral palsy. With on going active physiotherapy, longer benefits from the injections can occur. A new guideline from the AAN and the child neurology society finds Injection Botulinum toxin type A to be an effective and generally safe treatment for spasticity in children and adolescents with $\mathrm{CP}$ but there is some risk of isolated cases of generalized weakness following its use. Chemical denervation using phenol injections are some times used in larger muscles where botulinum toxin would be ineffective. How ever there is insufficient data to support or refute the use of phenol or alcohol ${ }^{25}$.

\section{Non- pharmacological therapy}

Selective dorsal rhizotomy (SDR) : Selective dorsal rhizotomy is a well accepted neurosurgical procedure for the relief of lower limb spasticity in children with spastic diplegic $\mathrm{CP}^{36}$. SDR plus physical therapy decreases spasticity, improves joint range of motion and have a positive effect on gross motor function, and gait ${ }^{26}$.

Neuromuscular electrical stimulation (NMES) : There is evidence to support the use and effectiveness of NMES in children with CP. Electrical stimulation to the hip adductor and abductor muscles simultaneously at the sensory and motor levels respectively improves the gait of spastic diplegic CP children ${ }^{38}$. How ever the use of dynamic splinting with NMES has been shown to be more effective than either treatment along on its own in improving function and posture. A neurostimulation device (the L 300 Foot Drop System), for the treatment of footdrop in children with cerebral palsy, was the first device of its kind approved by the US Food and Drug Administration (FDA) in January 2013 for use in children ${ }^{27}$.

Orthotic management in cerebral palsy: Children with $\mathrm{CP}$ may have many musculoskeletal deformities depending on the type of CP. Rehabilitation, orthopedic surgical intervention and additional orthotic management can prevent and correct these deformities. Orthoses are frequently used to improve the gait efficiency of ambulant children with $\mathrm{CP}$ and the most common orthoses used is the ankle-foot orthoses(AFO) ${ }^{28}$.

Rehabilitation: Traditional Physiotherapy and Occupational therapy are widely used interventions and have been shown to be of benefit in the treatment of cerebral palsy.Children with $\mathrm{CP}$ who require intensive physical, occupational and speech therapy may need to be admitted for rehabilitation. These patients receive therapy in at least 2 disciplines for 3 hours daily 29 .

Physiotherapy: Physiotherapy is the most common intervention in cerebral palsy and is usually a component of mandated program of management. Physiotherapy program consists of Neuro-developmental Treatment (NDT) and Therapeutic Exercises (TEs) 22 .

Occupational therapy (OT): Occupational therapy focuses on the development of skills necessary for the performance of activities of daily living. These activities include play, self-care activities such as dressing, grooming and feeding, and fine motor tasks such as writing and drawing. OT also addresses cognitive and perceptual disabilities, especially in the visual-motor area22.

Constraint-Induced Movement Therapy: Researchers report that children with $\mathrm{CP}$ who underwent C-I movement therapy saw a significant increase in grey matter volume in areas of the brain associated with movement ${ }^{30}$.

Training for sensory and perceptual integration: This is provided by giving various types of sensory stimulation. Most of this training is given in the form of play. Children not only accept this, they often enjoy learning these skills. 
Speech/Language Therapy : focuses on talking, using sign language, or using a communication aid $^{26}$.

Vagal nerve stimulation (VNS) : Jaseja has shown the efficacy of VNS in CP patients on account of its dual therapeutic effectiveness, i.e. anti-epileptic and IED-suppression. These two effects are likely to control seizures that are quite often drug-resistant and also improve neurocognition in $\mathrm{CP}$ patients, thus hoping for a better overall prognostic outcome and an improved quality of life ${ }^{31}$.

Cognitive stimulation: Cognitive stimulation may be performed with an occupational therapy, physiotherapy, speech/language therapy ${ }^{32}$.

Developmental Therapy (DT) : The "developmental therapy" is best done in a holistic interdisciplinary approach that draws on the expertise of many specialists in different disciplines comprising of a physiotherapist, occupational therapist, speech and language therapist preferably under one roof ${ }^{33}$.

Nutritional support : Some $35 \%$ of children with CP are malnourished. They may have difficulty in coordinating their muscles in their tongue and mouth to chew and swallow correctly. Extra nutritional supplements may be necessary in order to prevent malnutrition. Speech therapy provides some aid in the form of muscle exercises that can develop the muscles around the mouth. Those who require NG tube feeding during the first year of life have a 5 -times greater mortality rate than children with oral feeding. Due to limitations of long term use of NG tube feeds, the American Academy for Cerebral Palsy and Developmental Medicine (AACPDM) addressed gastrostomy as an option for long -term treatment and supports gastrostomy as beneficial to most, but not all patients with $\mathrm{CP}^{34}$

Oral health : Drooling occurs in upto $30 \%$ of children with CP. Intrasalivary gland injection of botulinum toxin type $A$ is known to treat sialorrhoea effectively in children with $\mathrm{CP}^{35}$.

Bone Strength in Children with Cerebral Palsy : There are sufficient data to support that there may be significantly decreased bone mass in children with cerebral palsy. If there is evidence of vitamin $\mathrm{D}$ deficiency or poor dietary calcium intake, replacement would be appropriate- Several study showed that vitamin D and a third generation bisphosphonate (risedronate) have a larger increase in bone mineral density compared with children treated with vitamin $\mathrm{D}$ alone.

Vitamin $\mathrm{K}$ : In a child with hemiplegia treated with vitamin $\mathrm{K}$ alone, the cortical bone geometric strength of the hemiplegic tibia increased compared with the non-hemiplegic tibia ${ }^{36}$.

New advances : In a study, allogenic umbilical cord blood (UCB) infusion potentiated with recombinant human erythropoietin (rhEPO) ameliorated motor and cognitive impairment in children with $\mathrm{CP}$, suggesting that this therapy could be developed as a novel therapeutic approach. A comprehensive evaluation of the adverse effects of this therapy is, however, necessary before its clinical application. Rabbits with CP treated with D-NAC, a dendrimer coupled with a drug known as NAC (N-acetyl-L-cysteine) showed a dramatic improvement and within 5 days were able to walk and hop. While still in pre-clinical testing in animals, the dendrimer-drug conjugate shows promise for postnatal treatment of babies suspected of having $\mathrm{CP}^{37}$.

\section{Prognosis}

In general, Some children who sit between three and four years of age eventually walk, but most require aids or braces or have restricted functional ambulation. A child who does not walk by nine years of age is unlikely to ever walk, even with support ${ }^{36}$. Overall, the probability of reaching the age of 20 years in child with severe CP is $50 \%$. Respiratory infections, aspiration, epilepsy, and cerebral malformation are leading causes of death ${ }^{38}$.

\section{Conclusion}

Various Medical efforts failed to prevent the occurrence of CP. CP is a very diverse diagnosis with substantial variation in impairments and severity. Care and research in childhood CP is evolving. Management is not curative; however, if provided optimally it can improve the quality of life of these children and their families.

\section{References}

1. Jan MMS. Cerebral palsy: Comprehensive Review and Update. Ann Saudi Med 2006; 26(2): 123-132

2. Rosenbaum $P$, Paneth $P$, Leviton $A$, Goldstein $M$, Bax M. A report: the definition and classification of cerebral palsy April 2006. Dev Med Child Neurol Suppl. 2007;109:8-14.

3. Oskoui $\mathrm{M}$, et al. An update on the prevalence of Cerebral Palsy: a systematic review and meteanalysis.Dev Med Child Neurol 2013;55960:509-519

4. Vincer MJ, Allen AC, Joseph KS. Increasing prevalence of cerebral palsy among very preterm infants: a population-based study. Pediatrics 2006;118(6):e1621

5. Stanley F, Blair E, Alberman E. Cerebral palsies: Epidemiology and Causal Pathways. London: Mackeith Press; 2000

6. Taft L. Cerebral Palsy. Pediatr Rev 1995; 16:411-418

7. Pschirrer R, Yeomans E. Does asphyxia cause Cerebral Palsy? Semin Perinatal 2000; 24:215-220

8. Jacobsson $B$ and Hagberg G. Antenatal risk factors for cerebral palsy. Best Pract Res Clin Obstet Gynaecol 2004;18(3):425-36.

9. Hoon A. Neuroimaging in the high risk infant: relationship to outcome. J Perinatal 1995; 15:389394

10. Garne E, Dolk H, et at. Cerebral Palsy and Congenital Malformations. Eur J Paediatr Neurol, 2008; 12(2): $82-88$

11. Self $L$, Shevel MI. A registry-based assessment of Cerebral Palsy and Congenital Malformations. J Child Neurol 2010; 25(11):1313-1318.

12. Moreno-De-Luca A,et al. Genomic insights into the causes and classification of Cerebral Palsies. The Lancet Neurology, 2012; DoI: 10.1016/51474-4422(11)70287-3.

13. Krigger K.W. Cerebral Palsy: An Overview. Am Fam Physician 2006;73(1):91-100.

14. Shevell MI, Bodensteiner JB. Cerebral Palsy: defining the problem. Semin Pediatr Neurol. 2004;11(1: 2-4)

15. Mathews D. Wilson P. Cerebral palsy. In: Molnar G, Alexander M (eds.). Paediatric Rehabilitation. $3^{\text {rd }}$ Ed. Philadelphia: Hanley and Belfus, INC; 1999:193.218.

16. Sanger TD, Delgado MR, Gaebler-Spira D, Hallett M, Mink JW. Task Force or Childhood Motor Disorder; Classification and definition of disorders causing hypotonia in childhood. Paediatrics 2003; 111; $889-97$

17. Himmelmann K, Hagberg G, Beckung E, Uvebrant P.The changing panorama of cerebral palsy in Sweden. IX. Prevalence and origin in the birth -year period 1995-1998.Acta Paediatr 2005;94: 287-294

18. Ashwal S, Russman BS, et al. Practice Parameter: Diagnostic Assessment of the Child with Cerebral Palsy. Report of the Quality Standard Subcommittee of the American Academy of Neurology and the Practice Committee of the Child Neurology Society. Neurology 2004; 62(6):851-863

19. Steven JK, Birbeck G, Delano MC, et al. A Systematic Review of Neuroimaging for Cerebral Palsy. J Child Neurol 2008;23(2):216-227.

20. Bax M, et al. Clinical and MRI Correlates of Cerebral Palsy: the European Cerebral Palsy Study. JAMA 2006;296(13):1602-1608

21. Towsley K, et al. Population-based Study of Neuroimaging findings in children with Cerebral Palsy. Eur J Paediatr Neurol 2011;15(1):29-35

22. Hoda Z. Abdel Hamid MD. Cerebral Palsy. Feb 2013. Emedicine, Medscape.com/article/1179555.

23. Greenwood VJ, et al. Immunization coverage in children with Cerebral Palsy compared with the general population. J Paediatr Child Health 2013;49(2): E 137-141.

24. Baker KW, Tann B, Mutlu A. Improvements in children with Cerebral Palsy following Intrathecal Baclofen. J. Child Neurol. Feb 2013. www.ncbi.nlm.nih.gov/pubmed/ 23420651

25. Delgado MR, et al. American Academy of Neurology guidelines evaluates treatments for children with Cerebral Palsy.Neurology 2010;74(4):336-343.

26. Armstrong RW. The first meta-analysis of randomized controlled surgical trials in Cerebral Palsy(2002). Dev Med Child Neurol 2008;8:54.

27. Anderson P. FDA clears stimulation system for Foot Drop in children. Medscape Medical News. Jan 2013. www.medscape.com/view article/778221

28. Morris $C$, et al.Orthotic management of cerebral palsy: recommendations from a consensus conference. Neurorehabilitation 2011; 28(1):37-46.

29. ThorogoodC, etal. Rehabilitation for cerebral palsy. Medscape June2011. emedicine. medscape. com/article/310740

30. Edward Taub. University of Alabama at Birmingham. CI therapy appears to benefit children with cerebral palsy.April 2013. www.news-medical.net/news/20130422.

31. Jaseja $\mathrm{H}$. Efficacy of vagal nerve stimulation in patients with cerebral palsy. Emerging corroborative evidence. Clin Neurol Neurosurg 2011; 113(7): 603.

32. Clinical Policy Bulletin 2010, 'Cognitive Rehabilitation'. Retrieved $24^{\text {th }}$ March,2010 from http://www.aetna.com/cpb/medical/data200_299/0214.html.

33. Sharna D. Recent advances in management of cerebral palsy'. Indian Journal of Pediatrics 2005; $72(1): 43-48$.

34. Samson-Fang L, Butler C, O'Donnell M, for the AACPDM. Effects of gastrostomy feeding in children with cerebral palsy: an AACPDM evidence report. Dev Med Child Neurol 2003;45:415.

35. Pei-Husan K, Ke J-Y et al. Botulinum toxin type A on oral health in treating Sialorrhoea with cerebral palsy. J Child Neurol 2011; 26(7):838-843.

36. Cohen $\mathrm{M}$, Lahat $\mathrm{E}$, Bistritzer $\mathrm{T}$, Livne $\mathrm{A}$, Heyman $\mathrm{E}$, Rachmiel $\mathrm{M}$. Evidence-based review of bone strength in children and youth with cerebral palsy. J Child Neurol 2009; 24: 959-967.

37. Nano drugs work in newborn rabbits. Journal Science Translational Medicine. April,2012. www.science daily/ April 18, 2012.

38. Hutton JL, Pharoah POD. Life expectancy in severe cerebral palsy. Arch Dis Child. 2006; 91(3):254258. 